\title{
Custo de capital das concessionárias de transmissão de energia elétrica no Brasil: um estudo da Companhia Estadual de Geração e Transmissão de Energia Elétrica - CEEE-GT
}

$\begin{array}{lr}\text { Thaís Mattei Lanziotti } & \begin{array}{l}\text { Universidade Estadual do Rio Grande do Sul, Especialização } \\ \text { em Gestão Pública, Porto Alegre, RS, Brasil. } \\ \text { Ricardo Letizia Garcia }\end{array} \\ \text { E-mails: thais.lanziotti@ceee.com.br } \\ \text { ricardo-garcia@uergs.edu.br }\end{array}$

Recebido em: 10 fev. 2017. Revisado em: 16 mar. 2017. Aceito: 20 abr. 2017. DOI: http://dx.doi.org/10.21674/2448-0479.42.320-339

\section{Resumo}

O artigo tem como objetivo demonstrar que o Custo de Capital regulatório fixado pela Agência Nacional de Energia Elétrica - ANEEL para as empresas Transmissoras de Energia Elétrica no Brasil está aquém dos reais custos de oportunidade de capital próprio e de recursos oriundos de capital de terceiros necessários aos investimentos empregados no setor. Dessa forma, realizou-se uma análise do custo de capital atual da Companhia Estadual de Geração e Transmissão de Energia Elétrica CEEE-GT, utilizando os mesmos parâmetros e metodologias de cálculo empregadas pelo Órgão Regulador, que consiste na combinação dos modelos CAPM (Capital Asset Pricing Model) e WACC (Weighted Average Cost of Capital).

Palavras-chave: Custo de Capital. Empresas de Transmissão de Energia. WACC. CAPM.

\begin{abstract}
Capital cost of electricity transmission concessioners in Brazil: a study of the state Company of Generation and Transmission of Electrical Energy - CEEE-GT

This article aims to demonstrate that the Regulatory Capital Cost established by the National Electricity Agency (ANEEL) for Electric Transmission Companies in Brazil falls short of the real opportunity costs of capital and capital resources from Necessary investments for the sector. The current cost of capital of the State Company Electric of Generation and Transmission of Electrical Energy (CEEE-GT) will be analyzed using the same parameters and calculation methodologies used by the regulatory organ, which is consisted by a combination of CAPM (Capital Asset Pricing Model) and WACC (Weighted Average Cost of Capital).
\end{abstract}

Keywords: Cost of Capital. Energy Transmission Companies. WACC. CAPM. 


\section{Introdução}

A importância da oferta de energia elétrica para o crescimento econômico brasileiro requer atenção especial à sustentabilidade e expansão deste serviço, sendo a determinação da adequada taxa de remuneração de capital, suficiente para cobrir os custos de oportunidade do capital próprio bem como do capital de terceiros empregado no setor, de extrema relevância para a continuidade dos investimentos. Uma vez que a manutenção e expansão do serviço público de transmissão de energia constituem obrigação contratual para as concessionárias, o estabelecimento de um custo de capital abaixo dos reais custos a que as empresas incorrem, podem gerar resultados catastróficos, como decréscimo dos investimentos e conseqüente deterioração da qualidade dos serviços, assim como se traduzirá em perdas econômicas para as empresas, alterando a viabilidade do negócio e a atração de capital ao setor. Portanto, a taxa de remuneração do investimento deve ser suficiente para cobrir o custo de oportunidade do capital próprio do investidor, bem como todos os custos atrelados ao capital de terceiros aplicado no projeto.

Para valorar o custo de capital das empresas transmissoras de energia elétrica brasileiras, a Agência Nacional de Energia Elétrica - ANEEL faz uso de uma combinação de modelos: o "Capital Asset Pricing Model" (CAPM) e o "Weighted Average Cost of Capital (WAAC). Ambos os modelos demonstram que a taxa de retorno de um empreendimento é uma média ponderada dos custos dos diversos tipos de capital, considerando a participação de cada tipo de capital no valor total dos ativos do empreendimento, ou seja, sua estrutura de capital. Considerando que o custo médio ponderado de capital estabelecido pelo Órgão Regulador data de 2013, e que, portanto, não mais suporta os custos efetivos dos financiamentos frente às atuais condições macroeconômicas do país, e ainda que a percepção de risco regulatório pelos agentes de crédito aumentou consideravelmente após as recentes mudanças ocorridas no setor através da Medida Provisória 579/2012, torna-se imperioso a revisão dos parâmetros utilizados pela Agência.

Assim, tomando-se como base o método atualmente utilizado pela ANEEL, buscou-se analisar o custo de capital real de uma concessionária do serviço público de transmissão, a Companhia Estadual de Geração e Transmissão de Energia Elétrica - CEEE-GT, visando evidenciar que a taxa de remuneração estabelecida pela Agência não é suficiente para suportar nas atuais condições, os custos de capital das concessionárias. Para tanto, realizou-se uma atualização dos índices de taxa livre de risco de mercado e risco país além da alteração dos coeficientes nas fórmulas de cálculo do CAPM.

Para atingir este objetivo, o presente artigo está organizado em cinco seções, incluindo a introdução. Para estudar o problema de pesquisa será feita, na primeira seção, uma revisão da literatura, enfatizando importantes princípios da teoria econômica a exemplo das diferentes estruturas de mercado, em especial o mercado monopolista, e da teoria de finanças corporativas, abordando conceitos de risco, retorno e custo de capital. $\mathrm{Na}$ segunda apresenta-se o método e os critérios gerais utilizados pelo órgão regulador na determinação do custo de capital aplicado no setor de energia elétrico brasileiro, bem como a demonstração dos resultados apurados no cálculo do custo médio ponderado de capital da Companhia Estadual de Geração e Transmissão de Energia Elétrica - CEEE- 
GT. Em seguida, tem-se a seção de materiais e métodos. Após, os resultados e discussões e, por fim, as conclusões obtidas ao longo do presente artigo.

\title{
A Estrutura de mercado do segmento de transmissão de energia
}

O setor elétrico, em especial as empresas do segmento de transmissão de energia elétrica são caracterizadas como monopólios naturais. O monopólio natural consiste em uma estrutura de mercado oposta à da concorrência, uma vez que apresenta falhas e imperfeições:

O monopólio pode ser definido como o extremo oposto da concorrência perfeita. A primeira condição para que se configure um caso típico de monopólio é a existência de apenas uma empresa, que domina inteiramente o mercado. Mas não basta esta condição. Pelo menos outras duas são, por definição, imprescindíveis: a inexistência de substitutos para o produto da empresa monopolista e a interposição de barreiras a entrada de concorrentes. (ROSSETTI, 2013, documento eletrônico)

As demais características presentes em um monopólio chamado puro ou natural e que resultam em barreiras à entrada de novos investidores tratam-se do alto volume de capital exigido no setor, e também as elevadas economias de escala que operam estas empresas. De acordo com Nogueira (1996, documento eletrônico):

Em geral, os mercados com monopólio natural apresentam algumas características comuns como por exemplo: a indústria deve ofertar um ou mais produtos ou serviços essenciais para a sociedade, os produtos ofertados por esta indústria devem ser não estocáveis fazendo com que a produção seja continuamente ajustada com a demanda e que seja ainda suficiente para atender aos períodos de pico, a indústria deve possuir elevadas economias de escala em relação a demanda de mercado.

Segundo Damodaran (2004, documento eletrônico):

\begin{abstract}
Alguns projetos somente obtêm retornos altos quando são feitos em escala suficientemente grande, restringindo assim a concorrência de empresas menores. Nestes casos, grandes companhias do setor podem ser capazes de continuar a obter retornos extras sobre seus projetos porque concorrentes menores não são capazes de imitá-los.
\end{abstract}

Em que pese que as empresas caracterizadas como monopólios naturais não têm seu preço determinado pelo equilíbrio de mercado, e, portanto, qualquer aumento deste preço tenderia a elevar a receita da companhia, já que a demanda para estes bens ou serviços é inelástica, as empresas do setor elétrico não dispõem de retornos extras, uma vez que estão sujeitas aos princípios de modicidade das tarifas ${ }^{1}$. A receita de uma empresa deste segmento não é definida pelo equilíbrio das forças

\footnotetext{
${ }^{1}$ Além dos princípios gerais do Direito Administrativo, há os princípios específicos previstos no artigo $6^{\circ}$ da Lei Rev. Elet. Cient. UERGS, v. 4, n. 2 (Número Especial), p. 320-339, 2018
} 
de mercado considerando quantidade demandada e ofertada, e sim estabelecida por um conjunto de regras pertencentes a um arcabouço regulatório, sendo o preço estabelecido e apurado pelo órgão regulador do setor. Assim como a receita das empresas é estabelecida pela ANEEL, o custo que remunera o capital investido no setor também o é. Tuma (2005, documento eletrônico) expõe:

\begin{abstract}
O mercado de energia elétrica é um monopólio natural, com todas as implicações econômicas que isto representa e possui, numa assertiva mais dramática, uma complexidade muito maior que outras atividades. A tese que aqui se propõe é que, qualquer idéia que não aquela que respeite o conceito de monopólio natural estará fadada ao insucesso; o único modelo que se reconhece factível atualmente no Setor Elétrico Brasileiro é o "cooperativo".
\end{abstract}

Uma vez que os preços no segmento de energia elétrica são regulados e sujeitos a um conjunto de regramentos estabelecidos pelo órgão regulador, a determinação de uma taxa de remuneração adequada, aderente aos custos e riscos incorridos pelo investidor do setor elétrico nacional, é de fundamental importância e consiste em tema de diversos trabalhos recentes de regulação econômica. Segundo Camacho (2004, documento eletrônico) ${ }^{2}$ :

De fato, é essencial que a taxa de retorno seja definida em um nível apropriado, que reflita o risco do ambiente regulado. Estimar uma taxa de retorno abaixo do custo de fundos do mercado pode tornar o investimento em novas plantas (ou até mesmo na expansão das redes) pouco atraente para os investidores do setor regulado. Tal fato pode ainda gerar maior pressão sobre o negócio, levando os investimentos para níveis abaixo do ótimo e à conseqüente degradação da qualidade do serviço. Por outro lado, se a taxa de retorno é estimada considerando um risco maior do que o realmente verificado, o negócio regulado irá se apropriar de uma taxa maior do que o custo de capital adequado. Isso acarretaria uma distorção dos sinais de preço, tanto para consumidores como para investidores, resultando em subalocação dos recursos e níveis de eficiência produtiva abaixo do nível ótimo.

Camacho (2006, documento eletrônico) ainda expõe:

A relevância da taxa de remuneração de capital estabelecida pela agência reguladora nos períodos de revisão tarifária é questão atual e presente em diversos trabalhos aplicados a setores de infra-estrutura e se justifica pelo reconhecimento de que, no longo prazo, o ente regulado deve recuperar pelo menos seu custo de oportunidade

“§ 1o Serviço adequado é o que satisfaz as condições de regularidade, continuidade, eficiência, segurança, atualidade, generalidade, cortesia na sua prestação e modicidade das tarifas."

${ }^{2}$ Documento eletrônico. 
de capital, incluindo o risco país, o risco do negócio, o risco regulatório e outros específicos dos projetos em que opera.

\section{Custo de capital empregado no setor}

A CEEE-GT, assim como as demais companhias de transmissão de energia brasileiras, tem sua Receita Anual Permitida - RAP, e, portanto, seu custo de capital, definidos pela ANEEL, através de metodologias e critérios constantes nos Procedimentos de Regulação Tarifária - PRORET, que consiste em instrumento normativo da Agência. O Submódulo 9.7 do PRORET exprime as metodologias aplicáveis no cálculo das parcelas de Receita Anual Permitida - RAP, cujo custo médio ponderado de capital é incorporado, além de parcelas de depreciação, remuneração por serviços de operação e manutenção e recomposição do custo anual dos ativos. A RAP atrelada a um investimento de expansão ou reforço de um ativo de transmissão é expressa pela seguinte equação 1:

$$
R_{B}=\frac{R_{L}}{(100 \%-P I S / C O F I N S-T F S E E-P \& D-R G R)}
$$

Onde:

$\mathrm{R}$ : receita líquida anual;

$R B$ : receita bruta anual;

PIS/COFINS: percentual relativo aos tributos PIS/PASEP e COFINS;

TFSEE: Taxa de Fiscalização dos Serviços de Energia Elétrica;

P\&D: percentual referente ao encargo de Pesquisa e Desenvolvimento;

RGR: percentual referente ao encargo de Reserva Global de Reversão.

A receita líquida anual, por sua vez, corresponde ao Custo Anual dos Ativos - CAA acrescido das despesas de Operação e Manutenção - COM, conforme equação 2:

$$
R_{L}=C A A+C O M
$$

Onde:

$\mathrm{R}$ : receita líquida anual;

CAA: Custo Anual dos Ativos;

COM: Custo de Operação e Manutenção.

O Custo Anual dos Ativos é calculado através da equação 3, e incorpora a parcela de remuneração de capital através do WACC regulatório: 


$$
C A A=\frac{I N V \cdot r_{\text {wacc }}}{(1-T)} \cdot\left(\frac{1}{1-\left(1+r_{\text {wacc }}\right)^{-1 / \delta}}-\frac{T}{r_{\text {wacc }} \cdot 1 / \delta}\right)
$$

Onde:

CAA: Custo Anual dos Ativos;

INV: Valor regulatório de investimento;

rwacc: taxa de retorno real depois dos impostos sobre a renda;

ð: taxa média de depreciação regulatória da Unidade Modular;

T: alíquota tributária marginal efetiva

Após a publicação da Medida Provisória $579^{3}$ de 11 de setembro de 2012, que dentre outros impactos, resultou na queda abrupta das receitas atreladas ao negócio transmissão, a ANEEL abriu, entre 04 de abril e 13 de maio de 2013, a Audiência Pública 031, visando obter subsídios para o aprimoramento das metodologias e critérios gerais para o Terceiro Ciclo de Revisão Tarifária Periódica das concessionárias de transmissão de energia elétrica. Para tanto, foram disponibilizadas as Notas Técnicas 075 de 22 de março de 2013, 077 de 26 de março de 2013, 196 de 29 de maio de 2013, bem como a minuta do Submódulo 9.1 dos Procedimentos de Regulação Tarifária - PRORET.

No Submódulo 9.1 dos Procedimentos de Regulação Tarifária, que tem por objetivo estabelecer os conceitos gerais, as metodologias aplicáveis e os procedimentos para revisão das receitas atreladas ao negócio transmissão de energia, é possível observar os parâmetros utilizados pela Agência na determinação do custo médio ponderado de capital vigente até o presente momento. Neste instrumento, a ANEEL demonstra o cálculo realizado para cada um dos componentes do WACC, que seja a estrutura de capital, o custo de capital próprio e o custo de capital de terceiros.

$\mathrm{Na}$ determinação da taxa de retorno para o custo de capital das empresas transmissoras de energia elétrica brasileiras, a ANEEL combina as metodologias WACC (Weighted Average Cost of Capital) e o modelo de precificação de ativos CAPM (Capital Asset Pricing Model).

Matematicamente o modelo CAPM tem como resultado a equação 4:

$$
\bar{R}_{i}=R_{f}+\beta_{i}\left(\bar{R}_{M}-R_{f}\right)
$$

Onde:

R̦i: retorno esperado do ativo ou carteira $\mathrm{i}$;

R̊f: taxa livre de risco

$\beta \mathrm{i}$ : beta do ativo ou carteira i (índice do risco sistemático)

ṚM: retorno esperado da carteira de mercado.

\footnotetext{
${ }^{3}$ Convertida na Lei 12.789/2013.
} 
O próprio órgão regulador do setor admite que o cálculo do CAPM ou do custo do capital próprio das empresas do setor de transmissão de energia elétrica brasileiras deveria considerar parâmetros locais, ao invés de globais (CAPM aplicado ao mercado de transmissão de energia elétrica dos Estados Unidos), determinando a taxa livre de risco, o prêmio de mercado e o beta sobre o mercado acionário nacional. Todavia, em razão de uma série de impeditivos colocados pela ANEEL, a exemplo de séries históricas insuficientemente extensas, baixa liquidez e desequilíbrios macroeconômicos que geram volatilidade nos ativos, torna-se impossível fazer uso dos dados locais. Em consequência, a Agência sugere a adaptação do risco associado às especificidades do mercado brasileiro. Para tal, adiciona à metodologia padrão, o prêmio de risco Brasil, conforme equação 5 :

$$
r_{C A P M}=r_{f}+\beta \cdot\left(r_{m}-r_{f}\right)+r_{B}
$$

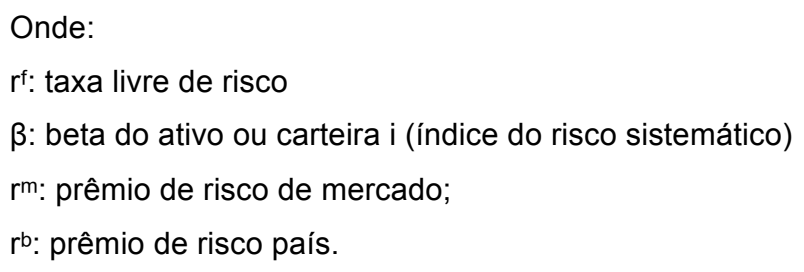

A estrutura de capital diz respeito às participações de capital próprio e de capital de terceiros no capital total investido por uma empresa. "A estrutura ótima de capital é definida como aquela estrutura que, dado o grau de risco envolvido no negócio e a existência de proteções fiscais para pagamentos de juros incidentes sobre a dívida, apresenta participações de capital (próprio e de terceiros) que conduzem ao mínimo custo de capital, representando, assim, uma alocação de capital eficiente" (BRASIL, 2013).

Para a definição da estrutura ótima de capital, a ANEEL utiliza dados de empresas licitadas com mais de cinco anos de operação, obtendo o valor para a estrutura ótima de capital após análise de $60 \%$ de participação de capital de terceiros. Para a taxa livre de risco, a ANEEL utiliza o rendimento do bônus do governo dos EUA com vencimento de 10 anos e duration ${ }^{4}$ de aproximadamente 8 anos. Para esse título, utilizou-se a média das taxas de juros anuais no período de janeiro de 1995 a dezembro de 2012, obtendo-se, através de média aritmética, uma taxa de juros anual média de $4,59 \%$. Já o prêmio de risco de mercado é calculado a partir da diferença entre os retornos médios da taxa livre de risco e do índice Standard \& Poor's 500 (S\&P500), que consiste num índice composto pelas ações das 500 maiores empresas negociadas na bolsa de Nova lorque. Com base nas séries históricas de 1928 a 2012, obteve-se uma taxa anual média (aritmética) de retorno do mercado acionário de 5,79\%.

Para se proceder ao cálculo dos Betas, foram utilizadas empresas americanas do setor de transmissão de energia elétrica membros do Edison Eletric Institute, associação que reúne empresas

\footnotetext{
${ }^{4}$ Prazo médio ponderado dos fluxos de caixa de um título. Reflete o tempo médio necessário para receber o valor presente dos fluxos de caixa desse título. (BANCO CENTRAL DO BRASIL. Disponível em: <www.bcb.gov.be>. Acesso em: 02 jun. 2016).
} 
do setor elétrico dos Estados Unidos que possuem capital aberto, representando aproximadamente $70 \%$ de toda a indústria nacional. De acordo com a ANEEL, o cálculo do beta envolve os seguintes passos: i) cálculo do beta alavancado para a amostra de empresas de energia elétrica dos EUA que apresentem a transmissão em suas atividades; ii) desalavancagem dos betas obtidos para cada empresa, utilizando-se o grau de alavancagem específico de cada empresa e a alíquota de $39,30 \%$ de imposto de renda dos EUA, obtendo-se o beta associado ao risco do negócio; iii) cálculo da média dos betas desalavancados, cujo resultado representa o beta desalavancado do setor; e iv) realavancagem do beta desalavancado do setor, usando-se a estrutura de capital estabelecida sob o enfoque regulatório e a alíquota de $34 \%$ de impostos, composta de $25 \%$ da alíquota do Imposto de Renda e 9\% de Contribuição Social Sobre o Lucro Líquido.

Selecionou-se 15 empresas, calculando-se os retornos semanais das ações no período de 5 anos, resultando no valor de 0,65. Considerando a estrutura média de capital destas empresas, e utilizando-se a alíquota de importo de $39,30 \%$, obteve-se o beta desalavancado médio de 0,44 . Calculando-se o beta de acordo com a estrutura de capital definida para as empresas brasileiras de $60 \%$, e com a carga de tributos de $34 \%$, a alavancagem do beta resultou em 0,88 , a ser aplicado no setor de transmissão de energia no Brasil.

Para determinação do prêmio de risco país, a ANEEL utiliza como indicador o EMBI (Emerging Markets Bond Index Plus), calculado pelo banco J. P. Morgan. Utilizou-se a mediana da série histórica diária do EMBI+Brasil de janeiro de 2000 a dezembro de 2012, resultando no valor mediano de $3,52 \%$. Destarte, com base na aplicação dos parâmetros apresentados, relacionados à taxa livre de risco, o prêmio de risco de mercado, o beta e o prêmio de risco país, a Agência determina o custo de capital próprio, em termos nominais, de 13,17\%. Para o custo de capital de terceiros, a ANEEL adota abordagem similar à do capital próprio, adicionando a taxa livre de risco aos prêmios de risco exigidos para se emprestar recursos a uma concessionária de transmissão de energia no Brasil:

$$
r_{d}=r_{f}+r_{C}+r_{B}
$$

Onde:

rd: custo de capital de terceiros;

rf: taxa livre de risco;

$\mathrm{rc}$ : prêmio de risco de crédito;

$\mathrm{rb}$ : prêmio de risco país.

O prêmio de risco de crédito deve representar o spread ${ }^{5}$ sobre a taxa livre de risco que pagam empresas com a melhor classificação de risco das transmissoras de energia elétrica brasileiras. Para tal, a ANEEL adota como benchmarking a melhor classificação de risco obtida entre as empre-

\footnotetext{
${ }^{5}$ Diferença entre taxas de juros de aplicação e de captação, compreendendo o lucro e o risco relativos às operações de crédito. Representa também a diferença entre o preço de compra e de venda de título ou moeda. Especifica o prêmio adicional que deve ser pago por um devedor em relação a uma taxa de referência. O spread varia de acordo com a qualidade de crédito do emissor, o prazo, as condições de mercado, o volume e a liquidez da emissão ou empréstimo. (BANCO CENTRAL DO BRASIL. Disponível em: $<$ www.bcb.gov.be $>$. Acesso em: 02 jun. 2016).
} 
sas brasileiras do setor elétrico, segundo a classificação da agência de risco Moody's, e aplica a referida classificação ao período de janeiro de 1995 a dezembro de 2012. Resultado do cálculo da média dos spreads ao longo da série determina-se uma taxa média de $2,01 \%$.

Assim sendo, o custo de capital de terceiros em termos nominais é fixado pela ANEEL em 10,11\%. De posse destes resultados, procede-se ao cálculo do custo médio ponderado de capital WACC.

O WACC é representado pela equação 7:

$$
r_{W A C C}=\frac{1+(P / V) \cdot r_{p}+(D / V) \cdot r_{d} \cdot(1-T)}{1+\pi}-1
$$

Onde:

rwacc: custo médio ponderado de capital após impostos, em termos reais;

$\mathrm{rp}$ : custo de capital próprio;

rd: custo de capital de terceiros;

$\mathrm{P}$ : capital próprio

D: capital de terceiros

V: soma do capital próprio e de terceiros;

$\mathrm{T}$ : alíquota tributária marginal efetiva;

m: inflação média dos EUA.

Após a Audiência Pública 031/2013, que contou com a contribuição de diversos agentes do setor, a ANEEL revisou o Submódulo 9.1 do PRORET de acordo com os resultados obtidos, apresentados no quadro abaixo:

Quadro 1- Custo Médio Ponderado de Capital

\begin{tabular}{|l|r|}
\hline \multicolumn{2}{|c|}{ CUSTO DE CAPITAL } \\
\hline Proporção de Capital Próprio & $40 \%$ \\
\hline Proporção de Capital de Terceiros & $60 \%$ \\
\hline Taxa livre de risco & $4,59 \%$ \\
\hline Prêmio de Risco de Mercado & $5,79 \%$ \\
\hline Beta médio alavancado & 0,88 \\
\hline Prêmio de Risco do Negócio & $5,07 \%$ \\
\hline Prêmio de Risco país & $3,52 \%$ \\
\hline Custo de Capital Próprio nominal & $13,17 \%$ \\
\hline Prêmio de Risco de Crédito & $2,01 \%$ \\
\hline Custo da Dívida nominal & $10,11 \%$ \\
\hline \multicolumn{2}{|c|}{ CUSTO MÉDIO PONDERADO } \\
\hline
\end{tabular}




\begin{tabular}{|l|l|} 
WACC nominal depois de impostos & $9,27 \%$ \\
\hline WACC real depois de impostos & $\mathbf{6 , 6 4 \%}$ \\
\hline
\end{tabular}

Fonte: BRASIL, 2013. ANEEL. Submódulo 9.1. PRORET

Logo, o WACC estabelecido pelo órgão regulador e vigente desde o ano de 2013 até o presente momento, e que integra as parcelas de RAP resultantes dos investimentos na expansão do serviço público de transmissão totaliza $6,64 \%$. A priori, esta taxa será revista apenas no próximo ciclo de revisão tarifária periódica no ano de 2018. A Revisão Tarifária ocorre em média a cada 5 (cinco) anos, de acordo com o contrato de concessão assinado entre as empresas e o poder concedente. $\mathrm{Na}$ revisão periódica são redefinidos, entre outros, o nível eficiente dos custos operacionais e a remuneração dos investimentos empregados, que consiste na definição do custo do capital.

\section{Materiais e Métodos}

O estudo faz uma ampla revisão da literatura sobre o custo de capital regulatório fixado pela Agência Nacional de Energia Elétrica - ANEEL para as empresas Transmissoras de Energia Elétrica no Brasil confrontando os custos de oportunidade de capital próprio e de recursos oriundos de capital de terceiros necessários aos investimentos empregados no setor.

Para tal, o estudo realiza uma análise do custo de capital atual da Companhia Estadual de Geração e Transmissão de Energia Elétrica - CEEE-GT, utilizando os mesmos parâmetros e metodologias de cálculo empregadas pelo Órgão Regulador, que consiste na combinação dos modelos CAPM (Capital Asset Pricing Model) e WACC (Weighted Average Cost of Capital).

\section{Resultados e Discussão}

Com base na metodologia e critérios utilizados pela ANEEL, procedeu-se ao estudo e apuração do custo de capital atual da Companhia Estadual de Geração e Transmissão de Energia Elétrica - CEEE-GT. A CEEE-GT é uma empresa de economia mista, pertencente ao grupo CEEE, concessionária dos serviços de geração e transmissão de energia elétrica no Estado do Rio Grande do Sul. É a responsável pela maioria das instalações que compõem a rede básica de transmissão do Estado, viabilizando o transporte e suprimento de energia às concessionárias de distribuição que atuam no RS: CEEE Distribuição, AES Sul, RGE, Concessionárias Municipais, Cooperativas de Eletrificação Rural e também a potenciais Consumidores Livres e Produtores Independentes.

O seu sistema de transmissão interliga usinas geradoras e o Sistema Interligado Nacional aos pontos de suprimento e centros de consumo em todo o Estado. As instalações de propriedade da CEEE e aquelas sob a sua responsabilidade, disponibilizadas para o Estado, são compostas por 66 subestações as quais, juntas, totalizam uma potência de 9.131,7 MVA (MegaVolt-Ampéres). Em linhas de transmissão a CEEE possui 6.055,61 km de extensão de linhas de transmissão que são su- 
portadas por 15.058 estruturas e operam nas tensões de 230, 138 e $69 \mathrm{kV}$ (quiloVolts). (COMPANHIA ESTADUAL DE ENERGIA ELÉTRICA, 2016).

No ano de 2012, com o advento da Medida Provisória 579 de 11 de setembro de 2012, teve renovada a sua concessão antecipadamente, perdendo aproximadamente $70 \%$ da sua Receita Anual Permitida - RAP, assim como as demais transmissoras. Neste cenário, tornou-se ainda mais imprescindível o estabelecimento de um custo de capital aderente aos riscos regulatórios a que o setor está sujeito.

De acordo com a metodologia constante no Submódulo 9.1 do PRORET, procurou-se analisar a estrutura de capital da companhia, seu custo de capital próprio e sua estrutura atual de financiamentos, que compõe o custo de capital de terceiros. Conforme as demonstrações financeiras da companhia no ano de 2015 , tem-se que o seu passivo total (circulante e não circulante) totaliza $R \$$ 1.436.870.000,00 e seu patrimônio líquido $\mathrm{R} \$ 1.481 .954 .000,00$ resultando em uma estrutura de capital de $49,23 \%$ de capital de terceiros e $50,77 \%$ de capital próprio.

\begin{tabular}{|c|c|c|}
\hline \multirow[b]{3}{*}{ R\$ Mil } & - Estrutura de Capital: & \\
\hline & \multicolumn{2}{|l|}{2015} \\
\hline & (Somente CEEE-GT) & Estrutura de $\mathrm{K}$ \\
\hline Passivo Circulante & 328.128 & \multirow{2}{*}{$49,23 \%$} \\
\hline Passivo Não-Circulante & 1.108 .742 & \\
\hline Patrimônio Líquido & 1.481 .954 & $50,77 \%$ \\
\hline
\end{tabular}

Para a taxa livre de risco, utilizou-se o rendimento do bônus do governo dos EUA com vencimento de 10 anos. Para esse título, utilizou-se a média das taxas de juros anuais no período de janeiro de 1995 a dezembro de 2015, obtendo-se, através de média aritmética, uma taxa de juros anual média de $6,58 \%$.

Quadro 3 - Taxa Livre de Risco

\begin{tabular}{|c|c|}
\hline Year & 10-year T. Bond \\
\hline 1995 & $23,48 \%$ \\
\hline 1996 & $1,43 \%$ \\
\hline 1997 & $9,94 \%$ \\
\hline 1998 & $14,92 \%$ \\
\hline 1999 & $-8,25 \%$ \\
\hline 2000 & $16,66 \%$ \\
\hline 2001 & $5,57 \%$ \\
\hline
\end{tabular}

\footnotetext{
${ }^{6}$ Documento eletrônico.
}

${ }^{7}$ Documento eletrônico. 
Fonte: STERN, $2016 .^{8}$

\begin{tabular}{|c|c|}
\hline 2002 & $15,12 \%$ \\
\hline 2003 & $0,38 \%$ \\
\hline 2004 & $4,49 \%$ \\
\hline 2005 & $2,87 \%$ \\
\hline 2006 & $1,96 \%$ \\
\hline 2007 & $10,21 \%$ \\
\hline 2008 & $20,10 \%$ \\
\hline 2009 & $-11,12 \%$ \\
\hline 2010 & $8,46 \%$ \\
\hline 2011 & $16,04 \%$ \\
\hline 2012 & $2,97 \%$ \\
\hline 2013 & $-9,10 \%$ \\
\hline 2014 & $10,75 \%$ \\
\hline 2015 & $1,28 \%$ \\
\hline Média aritmética & $\mathbf{6 , 5 8 \%}$ \\
\hline & \\
\hline
\end{tabular}

Para o prêmio de risco de mercado calculou-se a diferença entre os retornos médios da taxa livre de risco e do índice Standard \& Poor's 500 (S\&P500), observando as séries de 1928 a 2015, e obteve-se uma taxa anual média de retorno do mercado acionário de $6,18 \%$.

Quadro 4 - Prêmio de Risco Mercado

\begin{tabular}{|c|c|c|c|}
\hline Year & S\&P 500 & 10 -year T. Bond & Market Risk \\
\hline 1928 & $43,81 \%$ & $0,84 \%$ & $42,97 \%$ \\
\hline 1929 & $-8,30 \%$ & $4,20 \%$ & $-12,50 \%$ \\
\hline 1930 & $-25,12 \%$ & $4,54 \%$ & $-29,66 \%$ \\
\hline 1931 & $-43,84 \%$ & $-2,56 \%$ & $-41,28 \%$ \\
\hline 1932 & $-8,64 \%$ & $8,79 \%$ & $-17,43 \%$ \\
\hline 1933 & $49,98 \%$ & $1,86 \%$ & $48,12 \%$ \\
\hline 1934 & $-1,19 \%$ & $7,96 \%$ & $-9,15 \%$ \\
\hline 1935 & $46,74 \%$ & $4,47 \%$ & $42,27 \%$ \\
\hline 1936 & $31,94 \%$ & $5,02 \%$ & $26,92 \%$ \\
\hline 1937 & $-35,34 \%$ & $1,38 \%$ & $-36,72 \%$ \\
\hline 1938 & $29,28 \%$ & $4,21 \%$ & $25,07 \%$ \\
\hline 1939 & $-1,10 \%$ & $4,41 \%$ & $-5,51 \%$ \\
\hline 1940 & $-10,67 \%$ & $5,40 \%$ & $-16,07 \%$ \\
\hline 1941 & $-12,77 \%$ & $-2,02 \%$ & $-10,75 \%$ \\
\hline 1942 & $19,17 \%$ & $2,29 \%$ & $16,88 \%$ \\
\hline
\end{tabular}

\footnotetext{
${ }^{8}$ Documento eletrônico.
} 


\begin{tabular}{|c|c|c|c|}
\hline 1943 & $25,06 \%$ & $2,49 \%$ & $22,57 \%$ \\
\hline 1944 & $19,03 \%$ & $2,58 \%$ & $16,45 \%$ \\
\hline 1945 & $35,82 \%$ & $3,80 \%$ & $32,02 \%$ \\
\hline 1946 & $-8,43 \%$ & $3,13 \%$ & $-11,56 \%$ \\
\hline 1947 & $5,20 \%$ & $0,92 \%$ & $4,28 \%$ \\
\hline 1948 & $5,70 \%$ & $1,95 \%$ & $3,75 \%$ \\
\hline 1949 & $18,30 \%$ & $4,66 \%$ & $13,64 \%$ \\
\hline 1950 & $30,81 \%$ & $0,43 \%$ & $30,38 \%$ \\
\hline 1951 & $23,68 \%$ & $-0,30 \%$ & $23,98 \%$ \\
\hline 1952 & $18,15 \%$ & $2,27 \%$ & $15,88 \%$ \\
\hline 1953 & $-1,21 \%$ & $4,14 \%$ & $-5,35 \%$ \\
\hline 1954 & $52,56 \%$ & $3,29 \%$ & $49,27 \%$ \\
\hline 1955 & $32,60 \%$ & $-1,34 \%$ & $33,94 \%$ \\
\hline 1956 & $7,44 \%$ & $-2,26 \%$ & $9,70 \%$ \\
\hline 1957 & $-10,46 \%$ & $6,80 \%$ & $-17,26 \%$ \\
\hline 1958 & $43,72 \%$ & $-2,10 \%$ & $45,82 \%$ \\
\hline 1959 & $12,06 \%$ & $-2,65 \%$ & $14,71 \%$ \\
\hline 1960 & $0,34 \%$ & $11,64 \%$ & $-11,30 \%$ \\
\hline 1961 & $26,64 \%$ & $2,06 \%$ & $24,58 \%$ \\
\hline 1962 & $-8,81 \%$ & $5,69 \%$ & $-14,50 \%$ \\
\hline 1963 & $22,61 \%$ & $1,68 \%$ & $20,93 \%$ \\
\hline 1964 & $16,42 \%$ & $3,73 \%$ & $12,69 \%$ \\
\hline 1965 & $12,40 \%$ & $0,72 \%$ & $11,68 \%$ \\
\hline 1966 & $-9,97 \%$ & $2,91 \%$ & $-12,88 \%$ \\
\hline 1967 & $23,80 \%$ & $-1,58 \%$ & $25,38 \%$ \\
\hline 1968 & $10,81 \%$ & $3,27 \%$ & $7,54 \%$ \\
\hline 1969 & $-8,24 \%$ & $-5,01 \%$ & $-3,23 \%$ \\
\hline 1970 & $3,56 \%$ & $16,75 \%$ & $-13,19 \%$ \\
\hline 1971 & $14,22 \%$ & $9,79 \%$ & $4,43 \%$ \\
\hline 1972 & $18,76 \%$ & $2,82 \%$ & $15,94 \%$ \\
\hline 1973 & $-14,31 \%$ & $3,66 \%$ & $-17,97 \%$ \\
\hline 1974 & $-25,90 \%$ & $1,99 \%$ & $-27,89 \%$ \\
\hline 1975 & $37,00 \%$ & $3,61 \%$ & $33,39 \%$ \\
\hline 1976 & $23,83 \%$ & $15,98 \%$ & $7,85 \%$ \\
\hline 1977 & $-6,98 \%$ & $1,29 \%$ & $-8,27 \%$ \\
\hline 1978 & $6,51 \%$ & $-0,78 \%$ & $7,29 \%$ \\
\hline 1979 & $18,52 \%$ & $0,67 \%$ & $17,85 \%$ \\
\hline 1980 & $31,74 \%$ & $-2,99 \%$ & $34,73 \%$ \\
\hline 1981 & $-4,70 \%$ & $8,20 \%$ & $-12,90 \%$ \\
\hline 1982 & $20,42 \%$ & $32,81 \%$ & $-12,39 \%$ \\
\hline 1983 & $22,34 \%$ & $3,20 \%$ & $19,14 \%$ \\
\hline 1984 & $6,15 \%$ & $13,73 \%$ & $-7,58 \%$ \\
\hline 1985 & $31,24 \%$ & $25,71 \%$ & $5,53 \%$ \\
\hline
\end{tabular}


Fonte: STERN, 2016.

\begin{tabular}{|c|c|c|c|}
\hline 1986 & $18,49 \%$ & $24,28 \%$ & $-5,79 \%$ \\
\hline 1987 & $5,81 \%$ & $-4,96 \%$ & $10,77 \%$ \\
\hline 1988 & $16,54 \%$ & $8,22 \%$ & $8,32 \%$ \\
\hline 1989 & $31,48 \%$ & $17,69 \%$ & $13,79 \%$ \\
\hline 1990 & $-3,06 \%$ & $6,24 \%$ & $-9,30 \%$ \\
\hline 1991 & $30,23 \%$ & $15,00 \%$ & $15,23 \%$ \\
\hline 1992 & $7,49 \%$ & $9,36 \%$ & $-1,87 \%$ \\
\hline 1993 & $9,97 \%$ & $14,21 \%$ & $-4,24 \%$ \\
\hline 1994 & $1,33 \%$ & $-8,04 \%$ & $9,37 \%$ \\
\hline 1995 & $37,20 \%$ & $23,48 \%$ & $13,72 \%$ \\
\hline 1996 & $22,68 \%$ & $1,43 \%$ & $21,25 \%$ \\
\hline 1997 & $33,10 \%$ & $9,94 \%$ & $23,16 \%$ \\
\hline 1998 & $28,34 \%$ & $14,92 \%$ & $13,42 \%$ \\
\hline 1999 & $20,89 \%$ & $-8,25 \%$ & $29,14 \%$ \\
\hline 2000 & $-9,03 \%$ & $16,66 \%$ & $-25,69 \%$ \\
\hline 2001 & $-11,85 \%$ & $5,57 \%$ & $-17,42 \%$ \\
\hline 2002 & $-21,97 \%$ & $15,12 \%$ & $-37,09 \%$ \\
\hline 2003 & $28,36 \%$ & $0,38 \%$ & $27,98 \%$ \\
\hline 2004 & $10,74 \%$ & $4,49 \%$ & $6,25 \%$ \\
\hline 2005 & $4,83 \%$ & $2,87 \%$ & $1,96 \%$ \\
\hline 2006 & $15,61 \%$ & $1,96 \%$ & $13,65 \%$ \\
\hline 2007 & $5,48 \%$ & $10,21 \%$ & $-4,73 \%$ \\
\hline 2008 & $-36,55 \%$ & $20,10 \%$ & $-56,65 \%$ \\
\hline 2009 & $25,94 \%$ & $-11,12 \%$ & $37,06 \%$ \\
\hline 2010 & $14,82 \%$ & $8,46 \%$ & $6,36 \%$ \\
\hline 2011 & $2,10 \%$ & $16,04 \%$ & $-13,94 \%$ \\
\hline 2012 & $15,89 \%$ & $2,97 \%$ & $12,92 \%$ \\
\hline 2013 & $32,15 \%$ & $-9,10 \%$ & $41,25 \%$ \\
\hline 2014 & $13,52 \%$ & $10,75 \%$ & $2,77 \%$ \\
\hline 2015 & $1,36 \%$ & $1,28 \%$ & $0,08 \%$ \\
\hline \multicolumn{3}{|c|}{ Média aritmética } & $6,18 \%$ \\
\hline
\end{tabular}

No cálculo do beta, utilizou-se a covariância entre os retornos da ação EEEL4 ${ }^{9}$ e do IBOVESPA e a variância do IBOVESPA, para o período de 6 anos (de Jan/2010 a Dez/2015), obtendo-se o beta de 0,3778 a ser aplicado no cálculo do custo de capital próprio.

Quadro 5- Beta

\begin{tabular}{|l|c|c|c|}
\hline \multicolumn{2}{|c|}{ IBOVESPA } & \multicolumn{2}{c|}{ EEEL4 } \\
\hline Fech. & Var \% & Cotação Fech. & Var \% \\
\hline
\end{tabular}

\footnotetext{
${ }^{9}$ Ações Preferenciais- CEEE-GT
} 


\begin{tabular}{|c|c|c|c|c|c|c|}
\hline \multirow{12}{*}{ 웅 } & jan/10 & $65.401,77$ & & $\mathrm{R} \$$ & 210,00 & \\
\hline & fev/10 & $66.503,27$ & $1,68 \%$ & $\mathrm{R} \$$ & 201,00 & $-4,29 \%$ \\
\hline & $\mathrm{mar} / 10$ & $70.371,54$ & $5,82 \%$ & $\mathrm{R} \$$ & 350,00 & $74,13 \%$ \\
\hline & $a b r / 10$ & $67.529,73$ & $-4,04 \%$ & $\mathrm{R} \$$ & 350,00 & $0,00 \%$ \\
\hline & mai/10 & $63.046,51$ & $-6,64 \%$ & $\mathrm{R} \$$ & 400,00 & $14,29 \%$ \\
\hline & jun/10 & $60.935,90$ & $-3,35 \%$ & $\mathrm{R} \$$ & 400,00 & $0,00 \%$ \\
\hline & $\mathrm{jul} / 10$ & $67.515,40$ & $10,80 \%$ & $\mathrm{R} \$$ & 256,00 & $-36,00 \%$ \\
\hline & ago/10 & $65.145,45$ & $-3,51 \%$ & $\mathrm{R} \$$ & 200,00 & $-21,88 \%$ \\
\hline & set/10 & $69.429,78$ & $6,58 \%$ & $\mathrm{R} \$$ & 347,00 & $73,50 \%$ \\
\hline & out/10 & $70.673,30$ & $1,79 \%$ & $\mathrm{R} \$$ & 299,00 & $-13,83 \%$ \\
\hline & nov/10 & $67.705,40$ & $-4,20 \%$ & $\mathrm{R} \$$ & 314,00 & $5,02 \%$ \\
\hline & $\mathrm{dez} / 10$ & $69.304,81$ & $2,36 \%$ & $\mathrm{R} \$$ & 286,00 & $-8,92 \%$ \\
\hline \multirow{12}{*}{ ז্ণ } & jan/11 & $66.574,88$ & $-3,94 \%$ & $\mathrm{R} \$$ & 300,00 & $4,90 \%$ \\
\hline & fev/11 & $67.383,22$ & $1,21 \%$ & $\mathrm{R} \$$ & 262,00 & $-12,67 \%$ \\
\hline & $\mathrm{mar} / 11$ & $68.586,70$ & $1,79 \%$ & $\mathrm{R} \$$ & 256,00 & $-2,29 \%$ \\
\hline & $a b r / 11$ & $66.132,86$ & $-3,58 \%$ & $\mathrm{R} \$$ & 256,00 & $0,00 \%$ \\
\hline & mai/11 & $64.620,08$ & $-2,29 \%$ & $\mathrm{R} \$$ & 256,00 & $0,00 \%$ \\
\hline & jun/11 & $62.403,64$ & $-3,43 \%$ & $\mathrm{R} \$$ & 251,00 & $-1,95 \%$ \\
\hline & $\mathrm{jul} / 11$ & $58.823,45$ & $-5,74 \%$ & $\mathrm{R} \$$ & 300,00 & $19,52 \%$ \\
\hline & ago/11 & $56.495,12$ & $-3,96 \%$ & $\mathrm{R} \$$ & 257,00 & $-14,33 \%$ \\
\hline & set/11 & $52.324,42$ & $-7,38 \%$ & $\mathrm{R} \$$ & 245,00 & $-4,67 \%$ \\
\hline & out/11 & $58.338,39$ & $11,49 \%$ & $\mathrm{R} \$$ & 240,00 & $-2,04 \%$ \\
\hline & nov/11 & $56.874,98$ & $-2,51 \%$ & $\mathrm{R} \$$ & 230,00 & $-4,17 \%$ \\
\hline & dez/11 & $56.754,08$ & $-0,21 \%$ & $\mathrm{R} \$$ & 265,00 & $15,22 \%$ \\
\hline \multirow{12}{*}{ 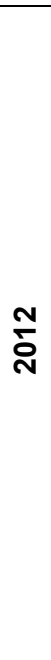 } & jan/12 & $63.072,31$ & $11,13 \%$ & $\mathrm{R} \$$ & 302,00 & $13,96 \%$ \\
\hline & fev/12 & $65.811,73$ & $4,34 \%$ & $\mathrm{R} \$$ & 340,00 & $12,58 \%$ \\
\hline & mar/12 & $64.510,97$ & $-1,98 \%$ & $\mathrm{R} \$$ & 340,00 & $0,00 \%$ \\
\hline & $a b r / 12$ & $61.820,26$ & $-4,17 \%$ & $\mathrm{R} \$$ & 298,00 & $-12,35 \%$ \\
\hline & mai/12 & $54.490,41$ & $-11,86 \%$ & $\mathrm{R} \$$ & 263,00 & $-11,74 \%$ \\
\hline & jun/12 & $54.354,63$ & $-0,25 \%$ & $\mathrm{R} \$$ & 289,00 & $9,89 \%$ \\
\hline & $\mathrm{jul} / 12$ & $56.097,05$ & $3,21 \%$ & $\mathrm{R} \$$ & 273,00 & $-5,54 \%$ \\
\hline & ago/12 & $57.061,45$ & $1,72 \%$ & $\mathrm{R} \$$ & 278,00 & $1,83 \%$ \\
\hline & set/12 & $59.175,86$ & $3,71 \%$ & $\mathrm{R} \$$ & 310,00 & $11,51 \%$ \\
\hline & out/12 & $57.068,18$ & $-3,56 \%$ & $\mathrm{R} \$$ & 292,00 & $-5,81 \%$ \\
\hline & nov/12 & $57.474,57$ & $0,71 \%$ & $\mathrm{R} \$$ & 292,00 & $0,00 \%$ \\
\hline & dez/12 & $60.952,08$ & $6,05 \%$ & $\mathrm{R} \$$ & 251,00 & $-14,04 \%$ \\
\hline \multirow{7}{*}{$\stackrel{m}{\sim}$} & jan/13 & $59.761,49$ & $-1,95 \%$ & $\mathrm{R} \$$ & 255,00 & $1,59 \%$ \\
\hline & fev/13 & $57.424,29$ & $-3,91 \%$ & $\mathrm{R} \$$ & 225,00 & $-11,76 \%$ \\
\hline & $\mathrm{mar} / 13$ & $56.352,09$ & $-1,87 \%$ & $\mathrm{R} \$$ & 169,00 & $-24,89 \%$ \\
\hline & $a b r / 13$ & $55.910,37$ & $-0,78 \%$ & $\mathrm{R} \$$ & 170,00 & $0,59 \%$ \\
\hline & mai/13 & $53.506,08$ & $-4,30 \%$ & $\mathrm{R} \$$ & 180,00 & $5,88 \%$ \\
\hline & jun/13 & $47.457,13$ & $-11,31 \%$ & $\mathrm{R} \$$ & 188,00 & $4,44 \%$ \\
\hline & jul/13 & $48.234,49$ & $1,64 \%$ & $\mathrm{R} \$$ & 160,00 & \begin{tabular}{|l|}
$-14,89 \%$ \\
\end{tabular} \\
\hline
\end{tabular}




\begin{tabular}{|c|c|c|c|c|c|c|}
\hline & ago/13 & $50.011,75$ & $3,68 \%$ & $\mathrm{R} \$$ & 155,00 & $-3,13 \%$ \\
\hline & set/13 & $52.338,19$ & $4,65 \%$ & $\mathrm{R} \$$ & 178,00 & $14,84 \%$ \\
\hline & out/13 & $54.256,20$ & $3,66 \%$ & $\mathrm{R} \$$ & 200,00 & $12,36 \%$ \\
\hline & nov/13 & $52.482,49$ & $-3,27 \%$ & $\mathrm{R} \$$ & 248,00 & $24,00 \%$ \\
\hline & dez/13 & $51.507,16$ & $-1,86 \%$ & $\mathrm{R} \$$ & 200,00 & $-19,35 \%$ \\
\hline \multirow{12}{*}{$\underset{\text { ¿্ }}{\mathbb{S}}$} & jan/14 & $47.638,99$ & $-7,51 \%$ & $\mathrm{R} \$$ & 185,00 & $-7,50 \%$ \\
\hline & fev/14 & $47.094,40$ & $-1,14 \%$ & $\mathrm{R} \$$ & 179,00 & $-3,24 \%$ \\
\hline & mar/14 & $50.414,92$ & $7,05 \%$ & $\mathrm{R} \$$ & 170,00 & $-5,03 \%$ \\
\hline & $a b r / 14$ & $51.626,69$ & $2,40 \%$ & $\mathrm{R} \$$ & 140,00 & $-17,65 \%$ \\
\hline & mai/14 & $51.239,34$ & $-0,75 \%$ & $\mathrm{R} \$$ & 132,00 & $-5,71 \%$ \\
\hline & jun/14 & $53.168,22$ & $3,76 \%$ & $\mathrm{R} \$$ & 150,00 & $13,64 \%$ \\
\hline & $\mathrm{jul} / 14$ & $55.829,41$ & $5,01 \%$ & $\mathrm{R} \$$ & 156,00 & $4,00 \%$ \\
\hline & ago/14 & $61.288,15$ & $9,78 \%$ & $R \$$ & 156,00 & $0,00 \%$ \\
\hline & set/14 & $54.115,98$ & $-11,70 \%$ & $\mathrm{R} \$$ & 156,00 & $0,00 \%$ \\
\hline & out/14 & $54.628,60$ & $0,95 \%$ & $\mathrm{R} \$$ & 112,00 & $-28,21 \%$ \\
\hline & nov/14 & $54.724,00$ & $0,17 \%$ & $\mathrm{R} \$$ & 119,00 & $6,25 \%$ \\
\hline & $\mathrm{dez} / 14$ & $50.007,41$ & $-8,62 \%$ & $\mathrm{R} \$$ & 147,00 & $23,53 \%$ \\
\hline \multirow{12}{*}{ 용 } & jan/15 & $46.907,68$ & $-6,20 \%$ & $\mathrm{R} \$$ & 125,00 & $-14,97 \%$ \\
\hline & $\mathrm{fev} / 15$ & $51.583,09$ & $9,97 \%$ & $\mathrm{R} \$$ & 148,00 & $18,40 \%$ \\
\hline & $\mathrm{mar} / 15$ & $51.150,16$ & $-0,84 \%$ & $\mathrm{R} \$$ & 148,00 & $0,00 \%$ \\
\hline & $a b r / 15$ & $56.229,38$ & $9,93 \%$ & $\mathrm{R} \$$ & 110,00 & $-25,68 \%$ \\
\hline & mai/15 & $52.760,47$ & $-6,17 \%$ & $\mathrm{R} \$$ & 130,00 & $18,18 \%$ \\
\hline & jun/15 & $53.080,88$ & $0,61 \%$ & $\mathrm{R} \$$ & 148,00 & $13,85 \%$ \\
\hline & $\mathrm{jul} / 15$ & $50.864,77$ & $-4,17 \%$ & $\mathrm{R} \$$ & 149,00 & $0,68 \%$ \\
\hline & ago/15 & $46.625,52$ & $-8,33 \%$ & $\mathrm{R} \$$ & 149,00 & $0,00 \%$ \\
\hline & set/15 & $45.059,34$ & $-3,36 \%$ & $\mathrm{R} \$$ & 110,00 & $-26,17 \%$ \\
\hline & out/15 & $45.868,81$ & $1,80 \%$ & $\mathrm{R} \$$ & 149,00 & $35,45 \%$ \\
\hline & nov/15 & $45.120,36$ & $-1,63 \%$ & $\mathrm{R} \$$ & 140,00 & $-6,04 \%$ \\
\hline & dez/15 & $43.349,96$ & $-3,92 \%$ & $\mathrm{R} \$$ & 94,00 & $-32,86 \%$ \\
\hline
\end{tabular}

Na determinação do prêmio de risco país, utilizou-se como a mediana da série histórica diária do EMBI+Brasil de janeiro de 2000 a dezembro de 2015, resultando no valor mediano de 2,73\%.

Assim, aplicando o modelo de precificação de ativos CAPM, conforme equação 8 tem-se que o custo de capital próprio da CEEE-GT em termos nominais é de $11,64 \%$.

$$
C A P M=6,58+0,3778 \cdot(6,18)+2,73
$$

Para a apuração do custo de capital de terceiros, observou-se os contratos de financiamento vigentes, firmados entre a CEEE-GT e agentes de crédito. Atualmente, a companhia possui recursos 
captados junto ao Banco Interamericano de Desenvolvimento - BID, a Agência Francesa de Desenvolvimento - AFD, o Banco Nacional de Desenvolvimento Econômico e Social - BNDES, as Centrais Elétricas Brasileiras SA - ELETROBRÁS, a Fundação CEEE de Previdência Privada - CEEEPREV e o Fundo de Investimento em Direitos Creditórios - FIDC junto a Caixa Econômica Federal - CEF.

Quadro 6 - Estrutura de financiamentos da CEEE-GT

\begin{tabular}{|c|c|c|c|c|c|c|}
\hline \multirow[b]{2}{*}{ Fonte } & \multirow[b]{2}{*}{ 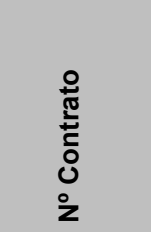 } & \multirow[b]{2}{*}{ 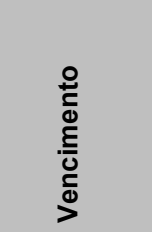 } & \multicolumn{4}{|c|}{ Custo (a. a.) } \\
\hline & & & $\begin{array}{l}\stackrel{0}{0} \\
\stackrel{2}{3}\end{array}$ & $\begin{array}{l}\frac{E}{0} \\
\dot{\chi} \\
\dot{x}\end{array}$ & 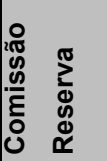 & 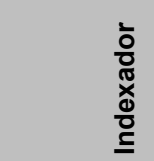 \\
\hline \multicolumn{7}{|l|}{ TOTAL MOEDA NACINAL } \\
\hline Moeda Nacional - Eletrobrás - RGR & SF 1360 & $30 / 06 / 2016$ & $5,00 \%$ & $2,00 \%$ & $1,00 \%$ & RGR \\
\hline Moeda Nacional - Fundação & SF1254-T & $31 / 05 / 2031$ & $6,50 \%$ & $0,00 \%$ & $0,00 \%$ & INPC \\
\hline Moeda Nacional - FIDC & SF 1359-T & $28 / 10 / 2017$ & $0,99 \%$ & $0,00 \%$ & $0,00 \%$ & $\mathrm{CDI}$ \\
\hline Moeda Nacional - BNDES & SF 1381 & $15 / 01 / 2029$ & $2,82 \%$ & $0,00 \%$ & $0,00 \%$ & TJLP \\
\hline \multicolumn{7}{|l|}{ TOTAL MOEDA EXTERNA } \\
\hline Moeda Externa - Dólar - BID & SF 1379 & $15 / 12 / 2036$ & $1,22 \%$ & $0,00 \%$ & $0,25 \%$ & Libor/Dólar \\
\hline Moeda Externa - Dólar - AFD & SF 1380 & $31 / 07 / 2036$ & $4,55 \%$ & $0,00 \%$ & $0,50 \%$ & Dólar \\
\hline
\end{tabular}

Fonte: Companhia Estadual de Energia Elétrica, $2016^{11}$.

Considerando-se o saldo devedor dos empréstimos e as variações dos indexadores de cada contrato ao longo do ano de 2015, tem-se que o custo médio anual da dívida da CEEE-GT é de $28,44 \%$.

\begin{tabular}{|c|c|c|c|c|c|c|c|c|c|c|c|c|}
\hline \multicolumn{13}{|c|}{ Quadro 7 - Custo Médio da Dívida } \\
\hline & Jan & fev & mar & abr & mai & jun & jul & ago & set & out & nov & dez \\
\hline TOTAL MOEDA NACIONAL & \multicolumn{12}{|c|}{ Custo relativo, considerando as variações mensais dos indexadores } \\
\hline Moeda Nacional - Eletrobrás - RGR & $0,43 \%$ & $0,42 \%$ & $0,39 \%$ & $0,36 \%$ & $0,33 \%$ & $0,31 \%$ & $0,28 \%$ & $0,23 \%$ & $0,20 \%$ & $0,16 \%$ & $0,02 \%$ & $0,02 \%$ \\
\hline Moeda Nacional - Fundação & $3,19 \%$ & $3,24 \%$ & $3,29 \%$ & $3,41 \%$ & $3,45 \%$ & $3,64 \%$ & $3,65 \%$ & $3,25 \%$ & $3,14 \%$ & $3,30 \%$ & $3,56 \%$ & $3,44 \%$ \\
\hline Moeda Nacional - FIDC & $1,33 \%$ & $1,29 \%$ & $1,23 \%$ & $1,22 \%$ & $1,17 \%$ & $1,17 \%$ & $1,13 \%$ & $0,99 \%$ & $0,93 \%$ & $0,93 \%$ & $0,94 \%$ & $0,83 \%$ \\
\hline Moeda Nacional - BNDES & $2,00 \%$ & $1,94 \%$ & $1,89 \%$ & $1,97 \%$ & $1,94 \%$ & $1,98 \%$ & $1,94 \%$ & $1,74 \%$ & $1,68 \%$ & $1,75 \%$ & $1,83 \%$ & $2,20 \%$ \\
\hline TOTAL MOEDA EXTERNA & & & & & & & & & & & & \\
\hline
\end{tabular}

${ }^{11}$ Companhia Estadual de Energia Elétrica. Custo anual da dívida: disponibilizado pelo Depto de Adm. Da Dívida - CEEE-GT, 2016. 


\begin{tabular}{|c|c|c|c|c|c|c|c|c|c|c|c|c|}
\hline Moeda Externa - Dólar - BID & $0,62 \%$ & $1,46 \%$ & $2,74 \%$ & $2,18 \%$ & $2,80 \%$ & $2,71 \%$ & $3,49 \%$ & $10,10 \%$ & $10,54 \%$ & $9,75 \%$ & $8,83 \%$ & $7,72 \%$ \\
\hline Moeda Externa - Dólar - AFD & $4,27 \%$ & $8,67 \%$ & $15,39 \%$ & $12,45 \%$ & $15,72 \%$ & $15,23 \%$ & $19,30 \%$ & $22,83 \%$ & $23,82 \%$ & $22,13 \%$ & $19,40 \%$ & $19,36 \%$ \\
\hline Custo médio da dívida & $11,85 \%$ & $17,03 \%$ & $24,92 \%$ & $21,58 \%$ & $25,42 \%$ & $25,05 \%$ & $29,78 \%$ & $39,14 \%$ & $40,30 \%$ & $38,02 \%$ & $34,59 \%$ & $33,58 \%$ \\
\hline Média aritmética & $28,4 \%$ & & & & & & & & & & & \\
\hline
\end{tabular}

Fonte: Companhia Estadual de Energia Elétrica, $2016 .^{12}$

Apurados o custo de capital próprio através da metodologia CAPM e o custo de capital de terceiros considerando os contratos de financiamento atuais da CEEE-GT, procedeu-se ao cálculo do custo médio ponderado de capital da Companhia Estadual de Energia Elétrica - CEEE-GT:

\begin{tabular}{|c|c|c|}
\hline \multicolumn{3}{|c|}{ Quadro 8 - Custo Médio Ponderado de Capital - CEEE-GT } \\
\hline Custo do Capital Próprio & $\mathrm{Kp}$ & $11,64 \%$ \\
\hline Taxa Livre de Risco em dólar & Rf & $6,58 \%$ \\
\hline Beta & $\beta \alpha$ & 0,3778 \\
\hline Prêmio de risco do mercado & PRM & $6,18 \%$ \\
\hline Risco País & $\mathrm{Rp}$ & $2,73 \%$ \\
\hline Inflação Americana (2015) & & $0,73 \%$ \\
\hline Custo do Capital de Terceiros & Kd & $28,44 \%$ \\
\hline Custo Médio Ponderado de Capital - nominal & WACC & $15,15 \%$ \\
\hline Percentual de Capital Próprio & CP & $50,77 \%$ \\
\hline Percentual de Capital de Terceiros & CT & $49,23 \%$ \\
\hline Alíquota Efetiva do imposto de Renda & IR & $34 \%$ \\
\hline Custo Médio Ponderado de Capital - real & WACC & $14,32 \%$ \\
\hline
\end{tabular}

Fonte: Companhia Estadual de Energia Elétrica, 2016.

Como resultado, obteve-se o WACC real de $14,32 \%$, observando a estrutura de capital e os custos de capital próprio e de terceiros da companhia. Esta taxa é consideravelmente superior ao WACC real determinado pela ANEEL de 6,64\%.

\section{Conclusão}

As empresas de transmissão de energia elétrica brasileiras sofreram recentemente as mudanças resultantes da promulgação da Medida Provisória 579/2012, cujos impactos mais relevantes consistiram na queda de receita e na alteração da percepção de risco regulatório pelos agentes de

\footnotetext{
${ }^{12}$ Companhia Estadual de Energia Elétrica - CEEE. Custo anual da dívida: disponibilizado pelo Depto de
} Adm. Da Dívida - CEEE-GT, 2016. 
crédito. Com a queda da RAP, somou-se a redução do índice de endividamento exigido pelos detentores de recursos de terceiros, gerando dificuldades ainda maiores na captação destes recursos.

Por outro lado, os investimentos em ativos de transmissão, para as concessionárias que possuem contratos de concessão deste serviço, são compulsórios e constituem obrigação contratual. Deixar de realizá-los implica em multas e penalidades para as companhias, e prejudicam sobremaneira a expansão e qualidade dos serviços. Não obstante, a determinação de um custo de capital que esteja aquém dos reais custos de oportunidade de capital próprio e de recursos de terceiros, pode gerar decisões empresariais intensivas em OPEX (Operational Expenditure), priorizando despesas operacionais em detrimento dos investimentos. A ANEEL é responsável pelo cálculo e estabelecimento do custo de capital empregado no setor de transmissão de energia, cujas revisões ocorrem a apenas a cada 5 anos. Tal modelo de regulação resulta em que as transmissoras incorram em prejuízos por longos períodos, se o custo de capital for estabelecido abaixo dos reais custos que incorrem as concessionárias.

Ao longo do presente artigo, demonstraram-se os métodos de cálculo utilizados pelo órgão regulador na determinação do custo médio ponderado de capital das empresas detentoras da concessão do serviço público de transmissão de energia elétrica no Brasil, bem como seu resultado, que exprime uma taxa de $6,64 \%$. Igualmente, demonstrou-se a aplicação dos mesmos critérios e metodologias na apuração do WACC para uma concessionária do serviço público de transmissão, a CEEEGT, que resultou na taxa de $14,32 \%$ de custo real do capital empregado em seus investimentos. Tal resultado demonstra claramente que o WACC fixado pela ANEEL, que teve sua última revisão no ano de 2013, está abaixo dos reais custos suportados por uma concessionária do serviço público de transmissão de energia, gerando diversas implicações negativas já citadas ao longo do presente artigo.

Neste ínterim, torna-se imperioso a revisão dos parâmetros utilizados pelo órgão regulador, bem como a revisão destes constantemente, de forma a acompanhar principalmente as mudanças macroeconômicas do país, a exemplo da inflação, taxas de juros e variação do câmbio, que tanto afetam o custo de capital de terceiros e a concessão de recursos pelos agentes de crédito.

\section{Referências}

BOLSA DE VALORES DO ESTADO DE SÃO PAULO. Custo de capital próprio IBOVESPA. 2016. Disponível em: <http://www.bmfbovespa.com.br>. Acesso em: 20 jun. 2016.

BRASIL. Agência Nacional de Energia Elétrica. Nota Técnica 075/2013 SRE/ANEEL. Brasília, DF: Ministério de Minas e Energia, 2013.

SUBMÓDULO 9.1. PRORET/ANEEL. 2013. Disponível em: <www2.aneel.gov.br/arquivos/PDF/Proret_Submódulo\%209.1.pdf>. Acesso: 26 jun. 2016.

CAMACHO, F. Aprimoramentos metodológicos para o custo de capital das concessionárias de transmissão de energia elétrica. Contribuição da Audiência Pública 001/2006, 2006. Disponível em: <http://www2.aneel.gov.br/aplicacoes/audiencia/arquivo/2006/001/contribuicao/fernando_camacho_1. pdf>. Acesso em: 15 jun. 2015. 
Cost of capital of regulated industries in Brasil. MPRA Paper, n. 5396, posted 22, October 2007.

COMPANHIA ESTADUAL DE ENERGIA ELÉTRICA - CEEE. Demonstrações Financeiras 2015 da CEEE-GT. 2016. Disponível em: < www.ceee.com.br>. Acesso em: 20 jun. 2016.

$$
\text { Geração e Transmissão. Disponível em: }
$$

<http://www.ceee.com.br/pportal/ceee/Component/Controller.aspx?CC=12457>. Acesso em: 26 jun. 2016.

DAMODARAN, A. Finanças Corporativas: teoria e prática. 2. ed. Porto Alegre: Bookman, 2004. NOGUEIRA, E. M. C. As recentes mudanças no setor elétrico: do monopólio à abertura de mercado. Dissertação (Mestrado). 1996. Escola de Pós-Graduação em Economia. Fundação Getúlio Vargas. São Paulo: 1996.

ROSSETTI, J. P. Introdução à economia. 20. ed. São Paulo: Atlas, 2013.

STERN. Annual Returns on Stock, T. Bonds and T.Bills: 1928 - Current. [2018]. Disponível em: $<$ http://pages.stern.nyu.edu/ adamodar/New_Home_Page/datafile/histretSP.html>. Acesso em: 20 jun. 2016.

TUMA, R. W. Sobre o monopólio natural e o modelo competitivo no setor elétrico brasileiro. Rio de Janeiro: IFE, 2005. 